\title{
Importance of changing photoperiod and melatonin secretory pattern in determining the length of the breeding season in the Suffolk ewe*
}

\author{
B. Malpaux†, J. E. Robinson $\ddagger$, M. B. Brown and F. J. Karsch \\ Consortium for Research in Developmental and Reproductive Biology, Department of Physiology \\ and Department of Biostatistics, The University of Michigan, Ann Arbor, Michigan 48109-0404, \\ U.S.A.
}

\begin{abstract}
Summary. Three groups of ovariectomized Suffolk ewes bearing s.c. Silastic implants of oestradiol were subjected to a 90-day priming treatment of an inhibitory long photoperiod (16h light/day; 16L:8D). On Day 0 of the experiment, they were moved to stimulatory photoperiods. One control group was transferred to $12 \mathrm{~L}: 12 \mathrm{D}$ and a second control group was transferred to $8 \mathrm{~L}: 16 \mathrm{D}$; both groups remained in those photoperiods to determine the timing of reproductive induction and refractoriness. The experimental group was transferred to $12 \mathrm{~L}: 12 \mathrm{D}$ on Day 0 and then to $8 \mathrm{~L}: 16 \mathrm{D}$ on Day 55 to determine whether the further reduction in daylength could delay the development of refractoriness. Reproductive neuroendocrine condition was monitored by serum concentrations of $\mathrm{LH}$ and FSH. Both gonadotrophins remained elevated for a longer period of time in the experimental group receiving the second reduction in daylength than in either control group, indicating that the second photoperiodic drop delayed the onset of photorefractoriness. Measurement of 24-h patterns of circulating melatonin suggests that the prolonged stimulation of reproductive neuroendocrine activity in the experimental group resulted from a lengthening of the nocturnal melatonin rise. These findings indicate that refractoriness to an inductive photoperiod can be temporarily overcome by exposure to a shorter daylength, and that the change in duration of the nocturnal increase in melatonin secretion is important in photoperiodic signalling. Thus, in natural conditions, the decreasing autumnal daylength, and the resulting expansion of the nocturnal elevation in melatonin secretion, may be utilized to produce a breeding season of normal duration.
\end{abstract}

Keywords: seasonal reproduction; photorefractoriness; melatonin; oestradiol negative feedback; photoperiodic history; sheep

\section{Introduction}

A loss of response to the ambient daylength (photorefractoriness) at certain times during the annual breeding cycle is a critical feature of the adaptive strategy of many seasonally breeding photoperiodic species. In many long-day breeders (e.g. starling, house sparrow, house finch, mallard, Japanese quail), photorefractoriness terminates the breeding season when the daylength is still long. This prevents the emergence of offspring at a time when the rearing of young could not be completed before the hardships of winter set in (Farner \& Follett, 1979). Termination of the breeding season

\footnotetext{
${ }^{*}$ Reprint requests to Professor F. J. Karsch.

$\dagger$ Present address: INRA, Station de Physiologie de la Reproduction, 37380 Nouzilly, France.

†Present address: AFRC Institute of Animal Physiology and Genetics Research, Cambridge Research Station,

Babraham, Cambridge CB2 4AT, U.K.
} 
by photorefractoriness is not restricted to long-day breeding species. In the short-day breeding sheep, for example, the transition from the breeding to anoestrous season is also associated with a loss of response to the stimulatory effects of the natural ambient daylength, in this case the short days of mid-winter (Lincoln, 1980; Worthy \& Haresign, 1983; Robinson \& Karsch, 1984).

Photorefractoriness can be evoked experimentally by prolonged exposure to a fixed photoperiod. Under controlled photoperiodic conditions, reproductive activity in the ewe can be induced by a single-step switch from a long day to an unchanging shorter daylength, but eventually ref ractoriness to that stimulatory signal develops and reproductive activity ceases (Karsch et al., 1986). The duration of the reproductive season under these artificial conditions, however, is considerably shorter than that in the natural photoperiod (2-3 compared to 5-6 month in our experimental conditions; Karsch et al., 1986; Malpaux et al., 1987). The purpose of the present study was to determine why such a difference in the length of the breeding season exists, thereby understanding how photoperiod regulates the length of the natural breeding season. An important distinction between those two situations is the specific photoperiodic signal: a constant short photoperiod in artificial conditions versus a progressively decreasing one outdoors during the late summer and autumn.

If refractoriness to a given stimulatory daylength could be overcome by a shorter photoperiod, then the progressively decreasing autumnal photoperiod could serve to extend the breeding season, relative to that in a constant inductive daylength, by continuously providing a more stimulatory photoperiod. This has been suggested from studies in certain species of birds (duck: Assenmacher \& Tixier-Vidal, 1962; quail: Robinson \& Follett, 1982). As an initial evaluation of such a role for decreasing autumnal daylength, we have tested the hypothesis that the development of refractoriness to a stimulatory short daylength can be delayed by exposure to a shorter photoperiod.

\section{Materials and Methods}

\section{Animals and treatments}

The study was performed with 16 sexually mature ewes which were purebred Suffolk or predominantly of the Suffolk breed. All ewes were 21 months of age at the start of the study; they had been maintained in light-sealed rooms under artificial photoperiod at the Sheep Research Facility in Ann Arbor, Michigan (latitude $42^{\circ} 18^{\prime} \mathrm{N}$ ) since 7 weeks of age. Ewes were fed hay daily and had free access to mineral licks and water. Daylength was regulated by an electronic timer that operated fluorescent bulbs providing approximately 350 lux lateral to the sheep's head. A dim red light producing less than 3 lux remained on continuously to facilitate night-time collection of blood for assay of melatonin.

The ewes were ovariectomized, and each was implanted s.c. with a Silastic capsule containing $30 \mathrm{~mm}$ of packed oestradiol-17ß 14 months before the study began (Karsch et al., 1973). The capsules were replaced at the beginning of the study and are known to produce serum oestradiol concentrations of $3-5 \mathrm{pg} / \mathrm{ml}$ (Legan et al., 1977; Legan \& Karsch, 1980). Reproductive neuroendocrine activity was assessed from the concentration of luteinizing hormone (LH) and follicle-stimulating hormone (FSH) in blood samples obtained twice weekly. In such animals, periods of elevated LH and FSH are indicative of the breeding season and periods of low LH and FSH are associated with anoestrus (Legan et al., 1977; Legan \& Karsch, 1980). The changes in gonadotrophin secretion in such ewes are photoperiodically mediated and they reflect a change in steroid negative feedback which constitutes a primary neuroendocrine mechanism for seasonal changes in ovarian cyclicity in ewes with intact ovaries (Legan \& Karsch, 1979, 1980). Therefore, we consider periods of elevated gonadotrophin secretion in the ovariectomized ewe treated with an oestradiol implant to be analogous to the 'breeding season'.

Before the start of the experiment, all ewes were pre-treated as follows to synchronize reproductive neuroendocrine activity: 65 long days ( $16 \mathrm{~h}$ light/day, $16 \mathrm{~L}: 8 \mathrm{D}$; lights on at $06: 00 \mathrm{~h}$ EST) followed by 90 short days $(8 \mathrm{~L}: 16 \mathrm{D}$, lights on at 06:00 h EST) and finally 90 long days (16L:8D) to establish reproductive inhibition and to maintain photosensitivity. On Day 0 of the experiment, animals were allocated to one of 3 groups and transferred to an inductive shorter daylength (Fig. 1). In Group $1(16 \rightarrow 12 \mathrm{~L} ; \mathrm{N}=5$ ), ewes experienced a 4-h reduction in photoperiod to 12L:12D; this was a control to determine the timing of reproductive neuroendocrine induction and refractoriness in that photoperiod. The ewes in Group $2(16 \rightarrow 12 \rightarrow 8 \mathrm{~L} ; \mathrm{N}=6)$ were moved to $12 \mathrm{~L}: 12 \mathrm{D}$ on Day 0 and then to $8 \mathrm{~L}: 16 \mathrm{D}$ on Day 55 (expected time of onset of gonadotrophin rise); this determined whether an additional reduction in daylength could delay the eventual development of photorefractoriness. The ewes in Group $3(16 \rightarrow 8 \mathrm{~L} ; \mathrm{N}=5)$ experienced an 8 -h reduction in photoperiod to $8 \mathrm{~L}: 16 \mathrm{D}$, and served as an additional control to determine whether the timing of reproductive neuroendocrine induction and refractoriness in the experimental group was a result of the 2-step reduction or the final daylength it experienced. Since the reproductive response to changes in photoperiod is known to be mediated 


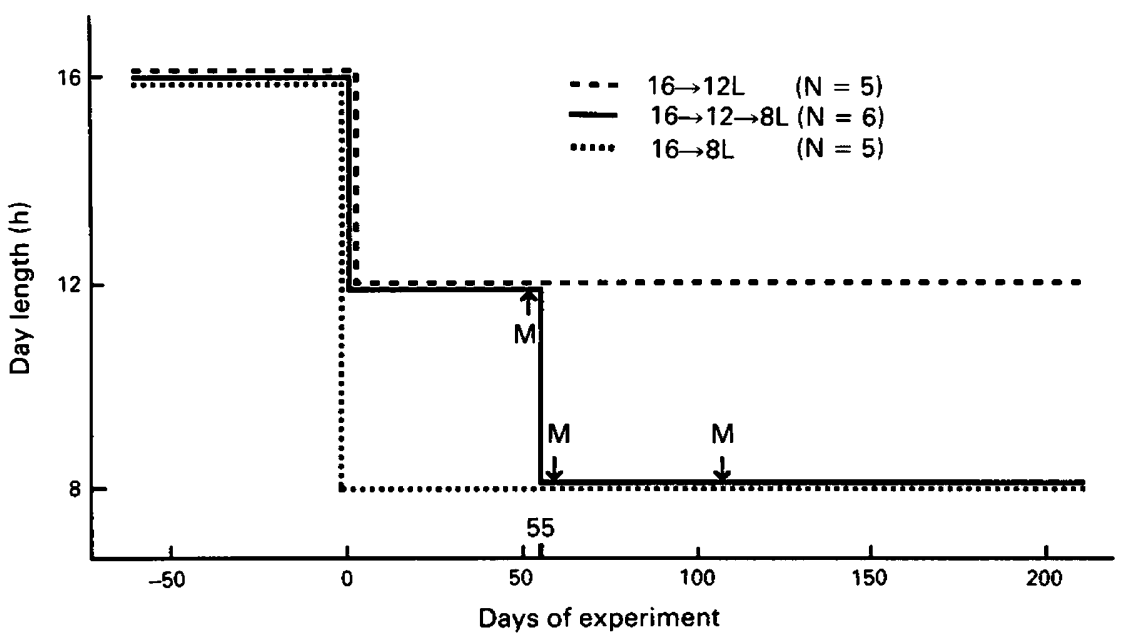

Fig. 1. Experimental design indicating the daylengths to which the 3 groups of ewes were exposed at the end of the priming period and during the 210-day experimental period (see text for details). $M$ indicates when 24-h profiles of circulating melatonin were determined in Group 2 $(16 \rightarrow 12 \rightarrow 8 \mathrm{~L})$. $\mathbf{N}=$ number of ewes per group.

by changes in the 24-h pattern of melatonin secretion, the pattern of circulating melatonin was determined 3 times in Group 2 ewes: once in 12L:12D (Day 50), 4 days after the transfer to 8L:16D (Day 59) and finally on Day 122 (Fig. 1). The experiment was terminated on Day 210.

\section{Blood sampling and assays}

Blood samples $(3-5 \mathrm{ml})$ were obtained by jugular venepuncture; serum was obtained and stored as described by Karsch \& Foster (1975). Samples were obtained twice a week (Tuesdays, Fridays) for assay of gonadotrophins. LH was assayed in duplicate $25-200 \mu \mathrm{l}$ samples of serum using the radioimmunoassay of Niswender et al. (1969) modified slightly as described by Hauger et al. (1977). Sensitivity (2 standard deviations from buffer control was $0 \cdot 23 \pm$ $0.03 \mathrm{ng} / \mathrm{ml}$ (mean \pm s.e.m., 8 assays) of NIH-LH-S12 for $200 \mu \mathrm{l}$. Intra-assay coefficient of variation (CV) for 3 serum pools determined 6 times in each assay averaged $5 \cdot 3 \%$ (8 assays); interassay CV for these serum pools averaged $6.7 \%$. FSH was assayed in duplicate 50-200 $\mu$ l samples of serum using the radioimmunoassay of L'Hermite et al. (1972) modified as described by Goodman et al. (1981). Sensitivity was $4.05 \pm 0.47 \mathrm{ng} / \mathrm{ml}$ ( 5 assays) of NIH-FSH-S8 for $200 \mu \mathrm{l}$. Intra-assay CV for 3 serum pools, determined 6 times in each assay, averaged $8.0 \%$ (5 assays); interassay CV for these serum pools averaged $7 \cdot 7 \%$. Blood samples for assay of melatonin were obtained every $2 \mathrm{~h}$ for $24 \mathrm{~h}$ starting at $09: 00 \mathrm{~h}$ EST, with 1-h samples being taken from $0.5 \mathrm{~h}$ before to $2.5 \mathrm{~h}$ after lights off and from $2.5 \mathrm{~h}$ before to $0.5 \mathrm{~h}$ after lights on. Melatonin was assayed in duplicate $200 \mu \mathrm{l}$ samples of serum using the radioimmunoassay of English et al. (1986) modified as described by Malpaux et al. (1987). The procedure was further modified in that quenching of radioactivity was prevented by incubating the supernatant, obtained after charcoal separation, with $100 \mu$ l hydrogen peroxide $(7.5 \%$ for at least $12 \mathrm{~h})$. This eliminated the need for quench correction. Sensitivity was $15 \cdot 7 \pm 3 \cdot 1 \mathrm{pg} / \mathrm{ml}$ (6 assays). Intra-assay CV for 2 serum pools determined 6 times in each assay averaged $10 \cdot 7 \%$ (6 assays); interassay $\mathrm{CV}$ for these serum pools averaged $8 \cdot 1 \%$.

\section{Analysis of data}

In this study, it was necessary to identify the times of change between four stages of the LH and FSH response. The four stages consist of baseline, rise, plateau and decline (followed by baseline, etc.). Since time series analysis and cosinor analysis do not identify the times of change, an algorithm was developed in this laboratory and applied to the results from each ewe individually. The algorithm consists of two steps.

Step 1. Starting at each time point, basic univariate and bivariate statistics (mean $=\mathrm{m}$, standard deviation $=\mathrm{s.d}$., slope of hormone with time $=$ slope, correlation squared of hormone with time $=r^{2}$ ) were calculated for the logarithm of the hormone value (LH or FSH) over a fixed number of consecutive time points. For our analyses 5 consecutive time points were used for each calculation. The statistics were computed for all starting times for which the 5-point sequences were available. The upper and lower quartiles (values which $25 \%$ of the computed statistics are greater than or less than, respectively) and the median were calculated for each sequence of statistics. These quartiles were then used in the second step. 
Step 2. Each time point was used as the centre of windows of consecutive points for which the above statistics were recomputed. The windows were of various lengths and contained 5, 7 and 9 points for this analysis. For each time point, the minimum s.d. (for the 3 possible windows), the minimum $r^{2}$ (that nearest zero), the maximum s.d., the maximum slopes (both positive and negative) and the maximum $r^{2}$ were evaluated.

The four stages were identified in the following manner: for baseline or plateau, minimum $r^{2}$ was less than its lowest quartile and/or minimum s.d. was less than the median; for rise (decline), maximum $r^{2}$ was greater than the upper quartile and slope was positive (negative), and/or maximum (minimum) slope was greater than the upper (less than lower) quartile, and/or the maximum s.d. was greater than its median and the slope associated with the maximal $r^{2}$ was positive (negative).

Since criteria for more than one stage can be fulfilled simultaneously, the time point was assigned to the stage of the previous time point if it also fulfilled the criteria for that stage. It was also assumed that the usual sequence is baseline, rise, plateau, decline, baseline, etc. Therefore, when a change in stage was necessary, the time point was assigned to the nearest stage that follows in the usual sequence (i.e. baseline follows a decline and plateau follows a rise). The one exception to the above rules was that if the step selected was baseline or plateau, then the average of the hormone, $\mathrm{m}$, was examined; if it was below its lower quartile, baseline was assigned, and if above the upper quartile, plateau was assigned to the time point.

This algorithm is not a test for the existence of rises, but rather a uniform method of identifying the rises for series which can differ in their average signal strength (height) and variability. Since windows for adjacent time points overlap, statistical tests for the correlations and slopes would be inappropriate. Rises and declines are identified by a sufficiently high correlation between the concentration of the hormone and the time. However, since high correlations can occur because of a change in a single endpoint, the variability of the signal was also examined. Low variability indicates a stable signal, i.e. baseline or plateau. The width of the windows determines the sensitivity of the algorithm to noise (peaks consisting of one or two points). If the range in the width of the windows is large, then it is more likely to find a low $r^{2}$ for one of the windows in the neighbourhood of the noisy peak and therefore not classify the noise as a rise followed by a decline.

The statistical analysis for differences between treatment groups was applied to the times of onset of the different stages (rise, plateau, decline, baseline) and to the lengths of the individual stages. The Mann-Whitney two-sample rank test was used for that purpose.

\section{Results}

\section{Response to stimulatory daylengths}

Concentrations of serum LH and FSH throughout the experimental period followed the same general pattern in all 3 groups (Fig. $2 a$ for $\mathrm{LH}$, Fig. $2 b$ for FSH). Specifically, circulating concentrations of both gonadotrophins remained low ( $\mathrm{LH}<0.5 \mathrm{ng} / \mathrm{ml}$, FSH $<50 \mathrm{ng} / \mathrm{ml}$ ) for $5.5-60$ days after the initial reduction in daylength and then rose dramatically to maximum values around Days 70-80. Finally, concentrations of both gonadotrophins declined in all groups back to or near the baseline seen before the reduction in daylength on Day 0 , a manifestation of short-day refractoriness. However, the timing of this decline differed among treatments. In ewes exposed to the two-step drop in photoperiod (Group 2: $16 \rightarrow 12 \rightarrow 8 \mathrm{~L}$ ), the fall in LH and FSH was delayed relative to that in either control group exposed to just one reduction in daylength.

This difference in timing is illustrated further in Fig. 3 which summarizes LH responses among individual animals in all 3 groups (the same patterns were observed for FSH, data not shown). Ewes in Group 3 which experienced an 8-h reduction in photoperiod on Day 0 displayed an LH rise slightly later $(P<0.05)$ than did ewes in one of the two groups exposed to the 4-h decrease at this time (Group 2); this difference was not observed in the other group exposed to the 4-h reduction (Group 1 compared to Group 3, N.S.). There was no significant difference in the day of onset of the LH plateau among the 3 groups. No significant difference was found between the 2 control groups (Groups I and 3) in the time LH started to fall and the time it returned to baseline. In contrast, LH started to fall and returned to baseline later in ewes in Group 2 receiving the 2-step drop in daylength $(P<0.01$ compared to both control groups).

The duration of each of the stages of the LH elevation is shown in Fig. 4. The length of the rising stage was longer $(P<0.05)$ in Group 2 ewes than in those in Groups 1 and 3, presumably because the second photoperiod drop was given at the beginning of that stage (Day 55) and provided an additional stimulation. No difference in the length of the falling stage was found 


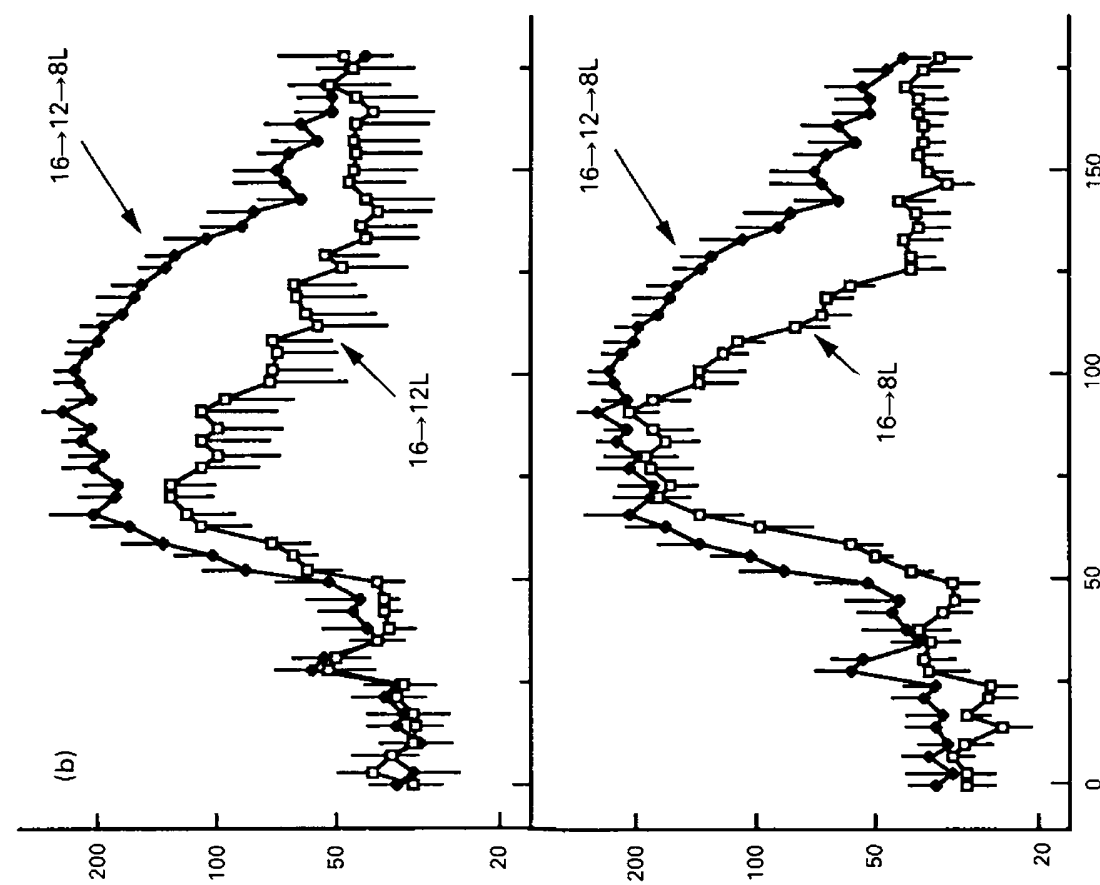

(ju/6u) HSJ
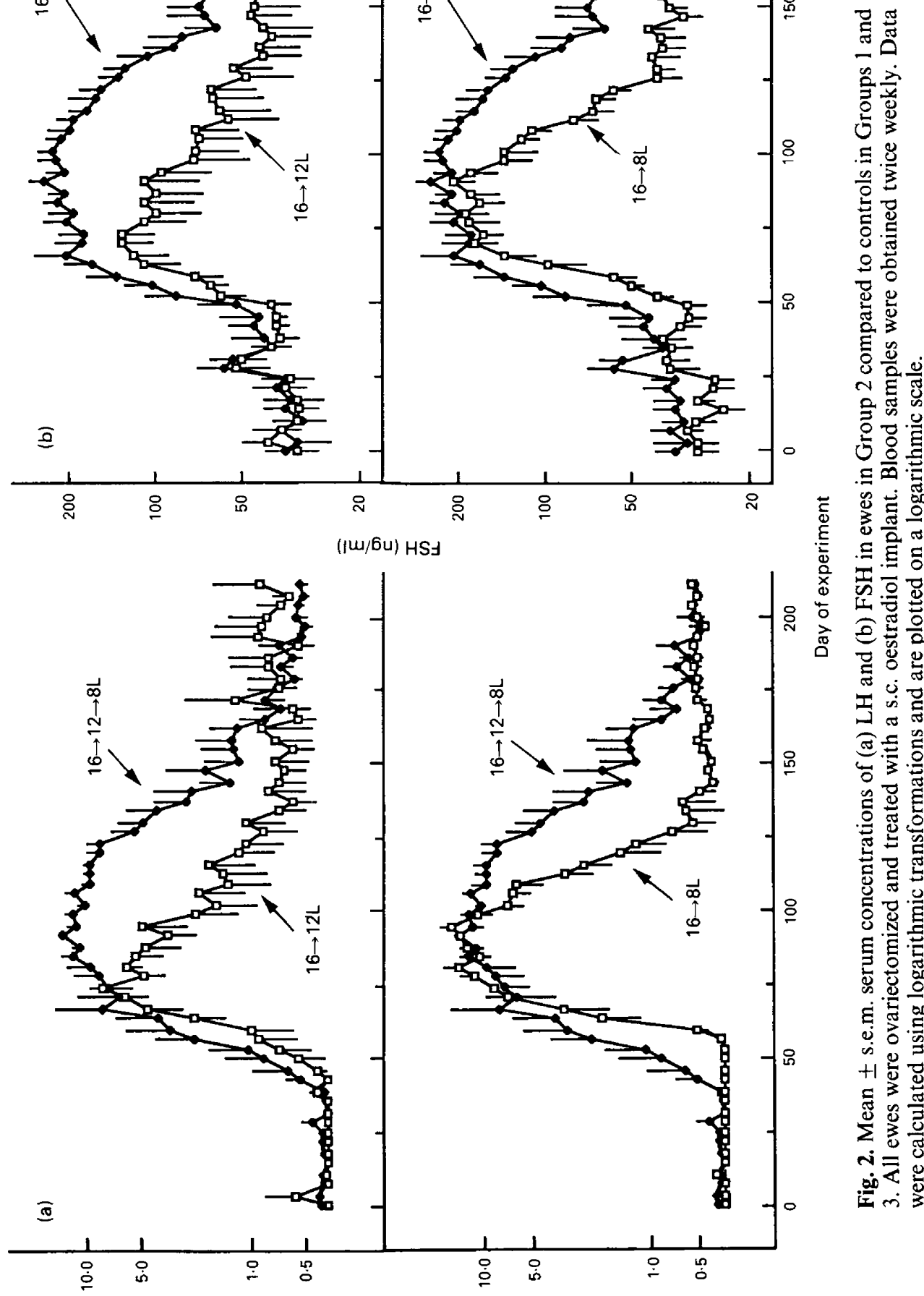

¿ $\rightleftarrows$

3 증

․ㅡㅁ

궁 웅

Tit:

은

원

ส

荘婄

ส․ㄹㄹ

岁药

पु है

串

政

远

记

․․ㄹ

ह ํㅡㄹ

总

घं

\% $\overrightarrow{0}$

+1

है

ब

$\sum \frac{3}{4}$

i”

काष

(|س/6u) Hา 


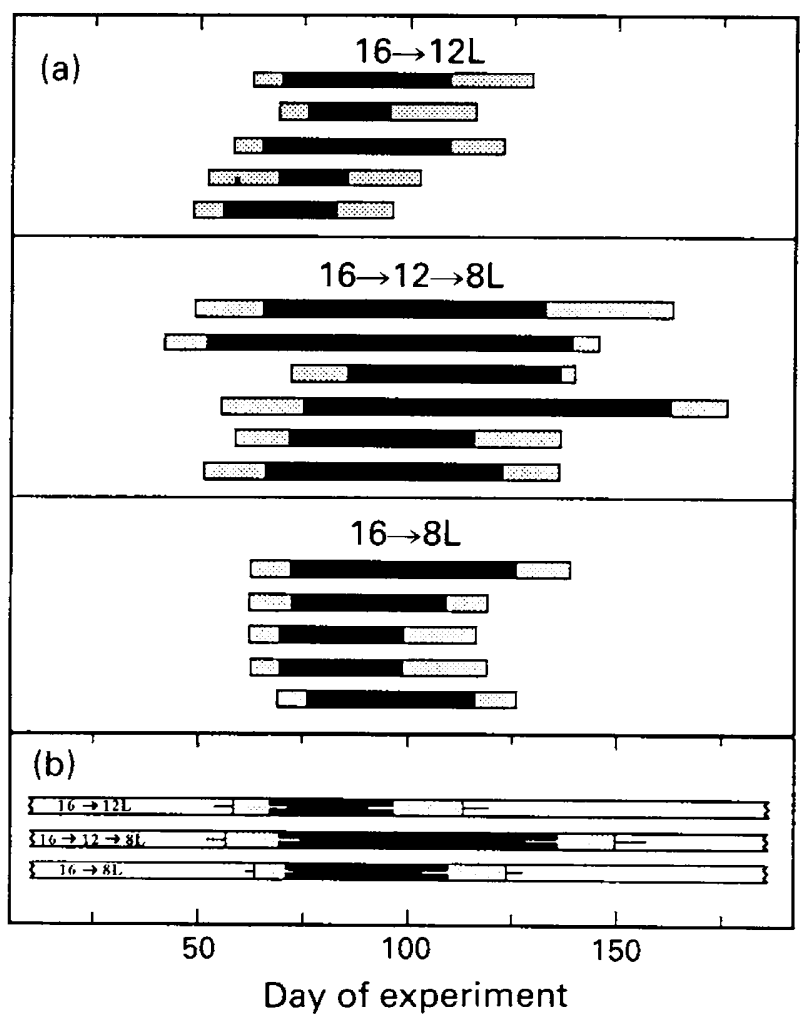

Fig. 3. Timing of the LH rise (see 'Materials and Methods') in (a) individual ewes in Groups 1,2 and 3 and (b) mean \pm s.e.m. times of transitions between stages of LH rise for the 3 groups. Stippled portions represent rising and falling LH concentrations; black portions represent plateau $\mathrm{LH}$ values.

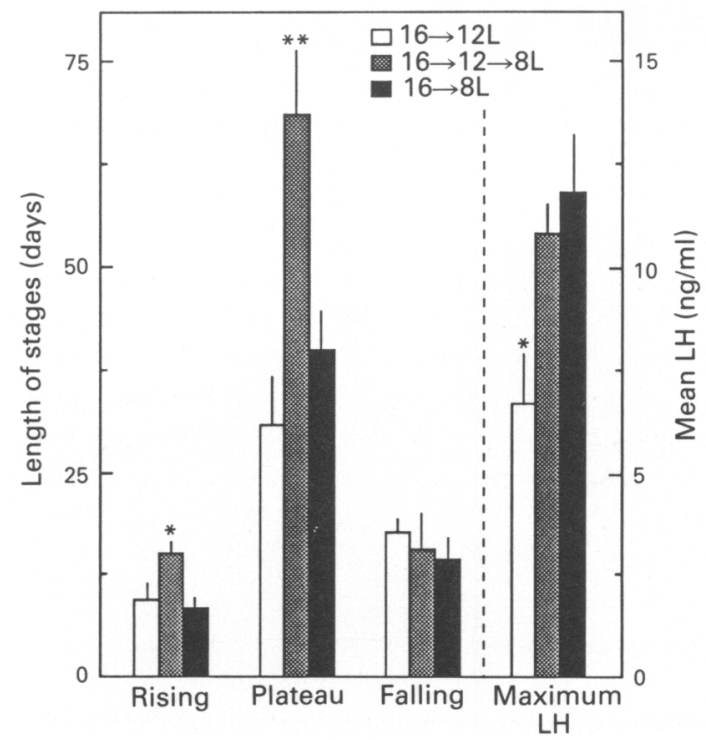

Fig. 4. Mean \pm s.e.m. durations of the rising, plateau and falling stages and mean serum value during the plateau stage of LH elevations in ewes in Groups 1,2 and $3 .{ }^{*} P<0 \cdot 05,{ }^{* *} P<0 \cdot 01$ compared to other groups. 

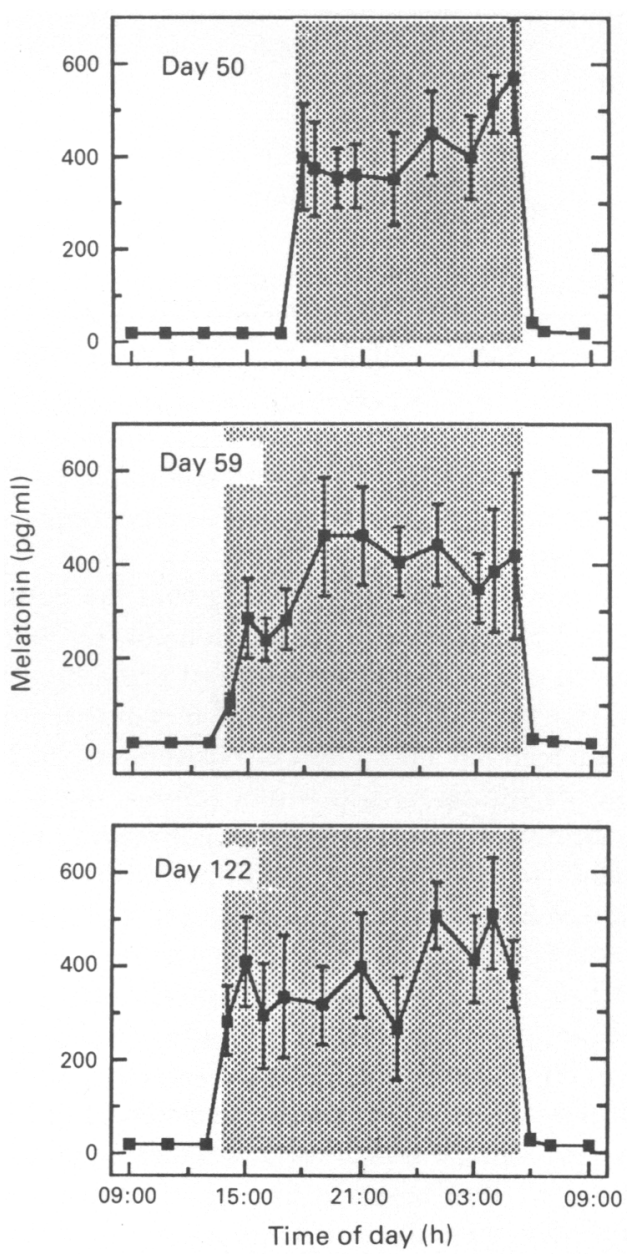

Fig. 5. Serum concentrations of melatonin during each $24-\mathrm{h}$ collection period for the ewes in Group 2 at Days 50, 59 and 122 of the experiment. Shaded areas depict periods of darkness. Each point is mean \pm s.e.m. for 6 ewes.

among groups. Importantly, the duration of the plateau stage (period of maximal stimulation) was approximately twice as long in Group 2 as in Groups 1 and $3(P<0.01)$. The total length of the LH rise was $99 \pm 9$ days in Group 2 ewes. This is still shorter $(P<0.01)$ than the LH elevation in oestradiol-treated ovariectomized ewes kept in natural photoperiod where the $\mathrm{LH}$ elevation lasted $181 \pm 21$ days $(\mathrm{N}=5)$ during the breeding season of $1984-1985$ when the experiment was performed.

The mean $\mathrm{LH}$ and FSH concentrations reached at the time of maximal stimulation (plateau stage) were lower $(P<0.05)$ in ewes in Group 1, which remained in 12L:12D than in those in Groups 2 and 3 which experienced the shorter daylength of $8 \mathrm{~L}: 16 \mathrm{D}$ (Fig. 4).

\section{Melatonin}

The 24-h patterns of serum melatonin concentrations in Group 2 on Days 50, 59 and 122 are shown in Fig. 5 (shift from 12L:12D to 8L:16D on Day 55). Without exception, on all 3 days, circulating concentrations of melatonin were high during darkness and low during the light phase. Therefore, the change in photoperiod on Day 55 caused approximately a 4-h increase in the length 
of the nocturnal secretion of melatonin; this increase was rapid and had occurred by Day 59,4 days after the daylength reduction.

\section{Discussion}

The time course of circulating LH and FSH observed in the present study leads to the conclusion that the development of refractoriness to an inductive photoperiod can be delayed by exposure to a shorter daylength. Specifically, the prolonged elevations in LH and FSH in ewes receiving the twostep drop in daylength compared to controls maintained in $12 \mathrm{~L}: 12 \mathrm{D}$ indicate that the second photoperiodic drop delayed the development of photorefractoriness. Further, the longer gonadotrophin elevations observed in the experimental group compared to the other group of controls maintained in $8 \mathrm{~L}: 16 \mathrm{D}$ indicates that this prolongation was a consequence of the two-step decrease rather than the final daylength experienced.

Our observations are also consistent with the finding that the natural breeding season can be prolonged by providing further photoperiodic stimulation shortly before the onset of anoestrus. Fraser \& Laing (1969) observed a delay in the cessation of breeding when ewes were moved from the natural photoperiod to a shorter daylength late in the breeding season, a finding which we have confirmed (unpublished). Along similar lines, Nett \& Niswender (1982) reported that daily afternoon injections of melatonin beginning in mid-winter, mimicking a daylength shorter than the ambient one, could prolong the breeding season of the ewe. Breeding activity can also be restored in ewes that are already refractory to a stimulatory photoperiod by transfer to a shorter daylength (T. J. Nicholls, G. L. Jackson \& B. K. Follett, unpublished). Collectively, results utilizing several different approaches lead to the conclusion that the timing of short-day refractoriness in the ewe is not absolute; rather it depends upon the specific photoperiodic history.

The pineal gland transduces photoperiodic information to the reproductive neuroendocrine axis of the ewe via the circadian rhythm of melatonin secretion (Bittman et al., 1983a, b). The pattern of circulating melatonin in ewes receiving the two-step photoperiodic reduction therefore becomes of considerable interest. The $24-\mathrm{h}$ profiles of circulating melatonin in these ewes provide evidence that the delay of photorefractoriness may have resulted from an alteration in the patterned secretion of melatonin. Specifically, the reduction in daylength from 12L:12D to 8L:16D caused an increase in the duration of nocturnal melatonin secretion; in both photoperiods, melatonin concentrations were elevated throughout the night. Earlier studies in the ewe demonstrate that refractoriness to an inductive photoperiod is due to a loss of response to a fixed melatonin pattern rather than a change in the pattern of melatonin secretion (Karsch et al., 1986; Malpaux et al., 1987). In the context of the present observations, this would suggest that ewes becoming unresponsive to a pattern of melatonin characterized by $12 \mathrm{~h}$ of secretion during a 12-h night are still sensitive to a pattern of melatonin of longer duration ( $16 \mathrm{~h}$ during a 16-h night). Thus, a changing duration of the night-time melatonin rise may be critical to the photoneuroendocrine timekeeping process.

Another interesting observation in this study is that the timing of the decline in LH and FSH was similar in the two control groups receiving the single-step reductions in daylength $(16 \rightarrow 12 \mathrm{~L}$ and $16 \rightarrow 8 \mathrm{~L}$ ). This complements previous findings in oestradiol-treated ovariectomized ewes in which the period of elevated LH was found to be of the same duration following a single-step photoperiodic shift from 16L:8D to $13 \cdot 5 \mathrm{~L}: 10 \cdot 5 \mathrm{D}$, 10L:14D or $8 \mathrm{~L}: 16 \mathrm{D}$ (J. E. Robinson \& F. J. Karsch, unpublished). The timing of photoneuroendocrine refractoriness in our studies does not therefore appear to be a function of the final daylength, at least for the $\mathbf{4}$ different photoperiodic reductions we have tested. The only difference we noted in the two control groups of the present study was a reduced magnitude of the LH and FSH rises in ewes exposed to the smaller decrease in photoperiod (i.e. $16 \rightarrow 12 \mathrm{~L}$ ), a finding also observed in earlier studies and probably a result of a weaker photostimulation (Robinson et al., 1985; Robinson \& Karsch, 1987). Our observations on the relationship between timing of refractoriness and length of the day identify a major 
difference between the sheep and those species of birds in which the timing of photorefractoriness has been studied. In the starling, for example, more stimulatory photoperiods appear to induce refractoriness more rapidly than less stimulatory ones (Dawson \& Goldsmith, 1983).

Finally, our current findings may be particularly relevant with regard to photoperiodic regulation of the duration of the breeding season of the ovary-intact ewe exposed to natural environmental conditions. The two-step reduction in daylength prolonged the duration of maximal reproductive stimulation, identified as a lengthening of the plateau stage of the LH and FSH response profiles. As suggested for the ram by Lindsay et al. (1984), a decreasing daylength may provide a more potent inductive signal than an abrupt decrease followed by a constant photoperiod. This, in turn, leads to the hypothesis that the decreasing autumnal daylength (and increasing duration of nocturnal secretion of melatonin) is utilized to delay the development of refractoriness and thus maintain a breeding season of normal duration. This also raises the possibility that the development of short-day refractoriness around the winter solstice may, in part, be a consequence of the fact that daylength is no longer decreasing. Experiments to test these hypotheses are in progress.

We thank Mr Douglas Doop and Kirk VanNatter for their assistance with the animal experimentation; Ms Barbara Glover for performing radioimmunoassays; Ms Nancy Wayne, Dr Douglas Foster, Dr Lee Claypool and Dr Francis Ebling for their help with collection of blood samples and their input in the design of this study; Dr Josephine Arendt, Dr Gordon Niswender and Dr Leo Reichert, Jr for supplying assay reagents; the Standard and Reagents Core Facility for preparing assay reagents, the Sheep Research Core Facility for maintaining the animals, and the Data Analysis Core Facility for processing the data. The work was funded by NSF-PCM-8316364 and NIH-P30-HD-18258; B.M. was supported by the Institut National de la Recherche Agronomique, France.

\section{References}

Assenmacher, I. \& Tixier-Vidal,A. (1962) La réactivité à divers agents de l'axe hypophyse-testicule du Canard traité à l'extrême début de la "période réfractaire" du cycle sexuel. C. r. hebd. Séanc. Soc. Biol., Paris 156, $267-272$.

Bittman, E.L., Dempsey, R.J. \& Karsch, F.J. (1983a) Pineal melatonin secretion drives the reproductive response to daylength in the ewe. Endocrinology 113, $2276-2283$.

Bittman, E.L., Karsch, F.J. \& Hopkins, J.W. (1983b) Role of the pineal gland in ovine photoperiodism: regulation of seasonal breeding and the negative feedback effects of estradiol upon luteinizing hormone secretion. Endocrinology 113, 329-336.

Dawson, A. \& Goldsmith, A.R. (1983) Plasma prolactin and gonadotrophins during gonadal development and the onset of photorefractoriness in male and female starlings (Sturnus vulgaris) on artificial photoperiods. $J$. Endocr. 97, 253-260.

English, J., Poulton, A.L., Arendt, J. \& Symons, A.M. (1986) A comparison of the efficiency of melatonin treatments in advancing oestrus in ewes. $J$. Reprod. Fert. 77, 321-327.

Farner, D.S. \& Follett, B.K. (1979) Reproductive periodicity in birds. In Hormones and Evolution, pp. 829-872. Ed. E. J. W. Barrington. Academic Press, London.

Fraser, A.F. \& Laing, A.J. (1969) Oestrus induction in ewes with standard treatments of reduced natural light. Vet. Rec. 84, 427-430.

Goodman, R.L., Pickover, S.M. \& Karsch, F.J. (1981)
Ovarian feedback control of follicle-stimulating hormone in the ewe: evidence for selective suppression. Endocrinology 108, 772-777.

Hauger, R.L., Karsch, F.J. \& Foster, D.L. (1977) A new concept for control of the estrous cycle of the ewe based on the temporal relationships between luteinizing hormone, estradiol and progesterone in peripheral serum and evidence that progesterone inhibits tonic LH secretion. Endocrinology 101, 807-817.

Karsch, F.J. \& Foster, D.L. (1975) Sexual differentiation of the mechanism controlling the preovulatory discharge of luteinizing hormone in sheep. Endocrinology 97 , 373-379.

Karsch, F.J., Dierschke, D.J., Weick, R.F., Yamaji, T., Hotchkiss, J. \& Knobil, E. (1973) Positive and negative feedback control by estrogen of luteinizing hormone secretion in the rhesus monkey. Endocrinology 92, 799804.

Karsch, F.J., Bittman, E.L., Robinson, J.E., Yellon, S.M., Wayne, N.L., Olster, D.H. \& Kaynard, A.H. (1986) Melatonin and photorefractoriness: loss of response to the melatonin signal leads to seasonal reproductive transitions in the ewe. Biol. Reprod. 34, 265-274.

Legan, S.J. \& Karsch, F.J. (1979) Neuroendocrine regulation of the estrous cycle and seasonal breeding in the ewe. Biol. Reprod. 20, 74-85.

Legan, S.J. \& Karsch, F.J. (1980) Photoperiodic control of seasonal breeding in the ewe: modulation of the negative feedback action of estradiol. Biol. Reprod. 23, $1061-1068$. 
Legan, S.J., Foster, D.L. \& Karsch, F.J. (1977) The endocrine control of seasonal reproductive function in the ewe: a marked change in response to the negative feedback action of estradiol on luteinizing hormone secretion. Endocrinology 101, 818-824.

L'Hermite, M., Niswender, G.D., Reichert, L.E., Jr \& Midgley, A.R., Jr (1972) Serum follicle-stimulating hormone in sheep as measured by radioimmunoassay. Biol. Reprod. 6, 325-332.

Lincoln, G. (1980) Photoperiodic control of seasonal breeding in rams-the significance of short-day refractoriness. In Endocrinology 1980, pp. 283-286. Eds I. A. Cumming, J. F. Funder \& F. A. O. Mendelsohn. Australian Academy of Science, Canberra.

Lindsay, D. R., Pelletier, J., Pisselet, C. \& Courot, M. (1984) Changes in photoperiod and nutrition and their effect on testicular growth of rams. J. Reprod. Fert. 71, 351-356.

Malpaux, B., Robinson, J.R. \& Karsch, F.J. (1987) Reproductive refractoriness of the ewe to inductive photoperiod is not caused by inappropriate secretion of melatonin. Biol. Reprod. 36, 1333-1341.

Nett, T.M. \& Niswender, G.D. (1982) Influence of exogenous melatonin on seasonality of reproduction in sheep. Theriogenology 17, 645-653.
Niswender, G.D., Reichert, L.E., Jr, Midgley, A.R., Jr \& Nalbandov, A.V. (1969) Radioimmunoassay for bovine and ovine luteinizing hormone. Endocrinology 84, 1166-1173.

Robinson, J.E. \& Follett, B.K. (1982) Photoperiodism in Japanese quail: the termination of seasonal breeding by photorefractoriness. Proc. R. Soc. B 215, 95-116.

Robinson, J.E. \& Karsch, F.J. (1984) Refractoriness to inductive day lengths terminates the breeding season of the Suffolk ewe. Biol. Reprod. 31, 656-663.

Robinson, J.E. \& Karsch, F.J. (1987) Photoperiodic history and a changing melatonin pattern can determine the neuroendocrine response of the ewe to daylength. J. Reprod. Fert. 80, 159-165.

Robinson, J.E., Radford, H.M. \& Karsch, F.J. (1985) Seasonal changes in pulsatile luteinizing hormone (LH) secretion in the ewe: relationship of frequency of LH pulses to day length and response to estradiol negative feedback. Biol. Reprod. 33, 324-334.

Worthy, K. \& Haresign, W. (1983) Evidence that the onset of seasonal anoestrus in the ewe may be independent of increasing prolactin concentrations and daylength. J. Reprod. Fert. 69, 41-48:

Received 9 October 1987 